Please quote as: Hoffmann, A.; Peters, C. \& Leimeister, J. M. (2011): Improving Corporate Portal Design by using Service-Oriented Requirements Engineering and Service Bundling. In: Requirements Engineering for Systems, Services, and Systems of Systems (RESS) 2011, Trento, Italy. 


\title{
IMPROVING CORPORATE PORTAL DESIGN BY USING SERVICE- ORIENTED REQUIREMENTS ENGINEERING AND SERVICE BUNDLING
}

\author{
Axel Hoffmann, Christoph Peters, Jan Marco Leimeister \\ Research Center for IS Design \\ Kassel University \\ Germany \\ \{axel.hoffmann|christoph.peters|leimeister\}@uni-kassel.de
}

\begin{abstract}
Portals are platforms combining services from various sources for various user groups. Service bundling from marketing can serve as a new way to enable mass customization of portal services for heterogeneous user groups using existing services. The purpose of this paper is to explore how service-oriented requirements engineering and service bundling can be combined in a new approach for the design of user-centric portals in order to achieve an advanced user experience on the service consumer side and improved service management on the service provider side. The success of both intended improvements is evaluated through the use of a case study. We combine service bundling from marketing with requirements engineering for web service based systems and develop a three step approach for designing portals: first, identifying user needs and matching them to existing adequate services provided by the organization; second, the decision makers negotiate all services according to user wishes and effort expectancy and determine the functionality of the portal; third, service bundling is used to build highly user-centric portal structures that are derived from the users' characteristic life events or demographic situations. The paper contributes to a new portal design that is fostered by usercentric service provision and high commitment of decision makers.
\end{abstract}

Keywords- Portal Development, Requirements Engineering, Service Bundling

\section{INTRODUCTION}

Portals are single points of entry to services that are dispersed throughout different sources and they present them homogenously to the user. The users do not need to use or even know the providing applications itself. While designing a portal, there arise questions on which services should be integrated. Decision makers will vote for as less expenses then necessary, users instead for all services possible. With focus on less expense, the additional value to the user of the portal will be low. But to avoid project fails because of high costs the decision makers as well as the users need to be involved.

Through the integration of many portal services the users' effort to find appropriate services does not necessarily decrease. A pre selection of services for specific user groups and independent from the providing applications can help. Pre-selection can be done according to situations or roles the user is belonging to. Thus, mass customization of the provided services can reduce effort the user needs to find appropriate portal services and help service providers to reach interested customer.

In the paper we answer the question how portals can be designed to provide benefit to the user and simultaneously consider the expected effort for the project. We combined service-oriented requirements engineering and service bundling from marketing to a new approach for the design of user-centric portals in order to reduce the effort on the service consumer side and improved service management on the service provider side.

Therefore, we clarify the understanding of services that differentiate in marketing and in computer science and show that the idea of service-oriented requirements engineering also works for corporate portals. Further, we explain how service bundling can be used to create views that offer additional value to the user.

In this paper, we present a new approach that fosters the engineering of portals through the joint use of serviceoriented requirements engineering and service bundling. In the next section we explain the meaning of services and outline the characteristics of portals. Further, we illustrate the most prominent challenges for the engineering of portals. Section IV describes the new approach and the interplay between service-oriented requirements engineering and service bundling. Then, the case is presented to which the new approach was applied. Finally, we report our findings and conclude with recommendations for future research directions.

\section{SERVICES AND PORTALS}

The term service is used differently in computer science, information science, and business science [1]. Therefore, we clarify the understanding of service and related terms in this paper. The first term we need to define is web service.

Web services "are operations that users access via the Internet through a well-defined interface independent of where the [web] service is executed" [2]. In service-oriented computing particular web services are used and they are only referred as services [1]. In this paper we use the term web service to distinguish them from (traditional) services like they are used in business science.

Services - in this case traditional services - "are business activities that often result in intangible outcomes or benefits; they are offered by a service provider to its 
environment" [1]. We will refer to this interpretation when we use the term service in the rest of this paper.

E-services are "services, where the Internet is used as a user interface, a channel to interact with the customers" [1]. Thus, e-services and web services are services provided by software applications. Web services have a well-defined interface that other software applications can easily access, e-service have an interface designed (only) for users.

Portals act as single points of entry to information sources and applications that are dispersed throughout different sources in the World Wide Web or internal information networks. A portal integrates services from different applications and offers them as a single application [3]. We name them portal services when they are selected to be part of a certain portal. In fact, portal services are eservices because they are provided by software applications, and the portal serves as a user interface. Technically, they are often provided by other software applications as web services to the portal.

Corporate portals offer users information and services related to their organization. From the perspective of an organization, portals have to integrate organizational structures, people, and processes [3]. Corporate portals face the challenge of addressing the needs of a heterogeneous group of users. In order to increase user acceptance, the most important critical success factor in portal projects [4], usercentric service provision, plays a key role.

Fundamental features of corporate portals are singlesign-on accessibility and customization. Single-sign-on requires a user to authenticate only once in order to access the provided services. Customization works in two ways. First, based on the user's profile, customization matches the services to the specific user. This is not under the control of the user since it needs to be done while developing the portal. Second, it enables users to edit and design their portal style, which means they can choose the specific content and services they prefer.

To provide a good fit for many users just from the beginning, a set of offered services depending on the various current users' backgrounds needs to be developed in advance [5]. This customization can be based on specific roles or job functions within the portal context and can be fostered through the adequate use of service bundling.

\section{Challenges In Portal ENGINEERING}

When we got the request for designing the student portal at Kassel University we tried to do it in the best way possible. It was clear that we had to deal with a lot of existing software applications. We found many challenges of portal engineering to be considered in the existing body of literature $[3 ; 4 ; 6 ; 7 ; 8]$, but only few methods which explicitly address challenges of portal engineering [3;8].

Challenges in portal engineering arise from the wide range of potential fields of application and from the large number of portal services a portal has to offer [3]. In portal engineering, the role of the requirements analysis phase will determine the project success in terms of evaluation and acceptance of the portal services [3]. To support user acceptance, Remus [4] suggests the intensive user integration within the portal development process. Further, portal integrators who are in charge of user consultation in portal implementation projects need a set of suitable instruments to support the entire development process [4].

Portals address a variety of possible application fields in specific contexts; however, it is nearly impossible to develop a portal solution that covers every aspect from the beginning [3]. The success of a portal initiative is driven by the users, as they need to understand the underlying goals and realize their benefits while working with the system [3]. Therefore, the selection of the portal services that need to be realized and deployed with the initial portal implementation "is one important foundation for the acceptance of the corporate portal implementation" [3].

Decision makers and project executives need to understand the evolutionary nature of a portal initiative [3]. To deploy a successful portal, the selection of the services according to the results of the requirement engineering is important, i.e. the requirements have to be categorized in a way that allows prioritization. First, it is crucial to focus on simple but useful services that provide users with clear benefits. Thus, users are attracted to and not overstressed with functionality-loaded portals that are hard to comprehend [3].

In addition to the wide range of potential application fields and the vast amount of portal services to cope with, the heterogeneousness of user groups represents a major challenge. Every group has specific requirements to the set of services which should be provided. Varying views can be used to address this challenge [6].

\section{Designing Corporate Portals}

The services which are offered by the organization need to be arranged in views that fulfill the need of different user groups. The views need to be designed in order to minimize the effort for the users. It would be annoying to browse hundreds of services to select appropriate ones or to recognize that certain services are not offered in the portal yet.

To build these views we use service bundling which combines services to create additional value for the users. Therefore, we need the whole set of services the portal can offer which is negotiated with the decision makers after required services are collected at the beginning with the user.

\section{A. Service-oriented Requirements Engineering}

In the first section, we have pointed out the benefits of service-orientation within a portal context. It becomes obvious that a service-oriented development approach would meet the needs of a corporate portal. Service-orientation in requirement engineering refers to the use of web service as type of prototypes that are already available during the requirements process [2]. It is used to build service-centric systems $[9 ; 10]$.

Service-oriented requirements engineering addresses new possibilities in service-centric system development and refrains from solution-free requirements [2]. With the growing amount of web services, a possible solution is (nearly) always available (accessible web services organized 


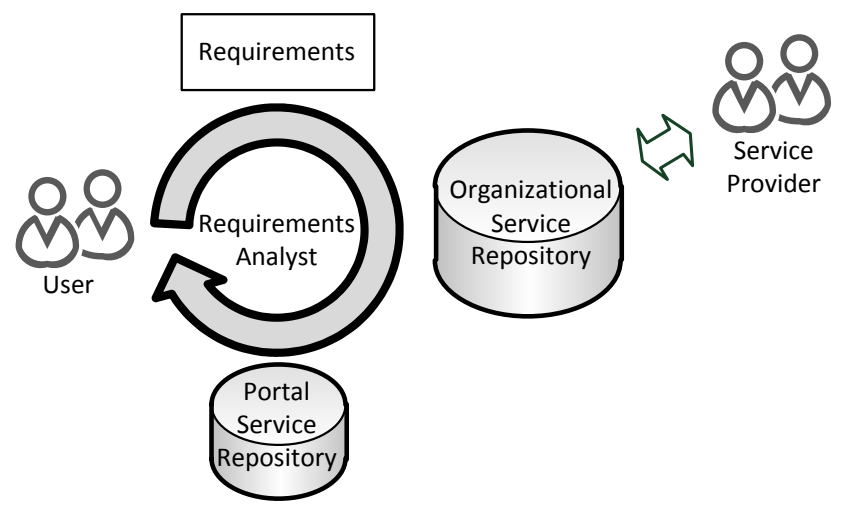

Figure 1. Matching Requirements with Services

in repositories) [10]. Thus, web services were identified to use them as possible components of the new application. These are presented to the user to clarify and improve the requirements [9].

Building a portal within an organization is a similar situation. There are many services offered to users that are provided by different IT applications or offline. Compared to the amount of available web services in the World Wide Web, services within one organization can be collected with manageable effort. Thus we can identify appropriate services offered within the organization during the user-supported requirements analysis phase (Figure 1).

Services were selected from the organizational service repository and collected in a portal service repository. This service repository is used to further analyze user requirements. The services can be used to describe and demonstrate the functionality. As in prototyping, this can help users identify whether the requirements were understood according to their needs or not. On this basis, it enables them to specify their requirements or formulate additional ones.

\section{B. Service Matrix and Negotiation}

Web services, e-services and services of the portal service repository are grouped in a service matrix. Therefore, we use two dimensions. First, the requirements analyst can provide information on how often a service is requested by different users during the requirements elicitation phase
(Figure 2, Requests). This indicates the importance of the requested service. Second, the services can be sorted by the expected effort (Figure 2, Effort Expectancy).

The three types of services can be distinguished by the effort needed for their portal integration. Web services provide a well-described technical interface. The integration in a portal needs only little effort.

The effort to integrate e-services depends on the providing software application, as it depends on the provided interfaces and the openness of the software. The access to proprietary closed software can be challenging and require a lot of effort. But the processes and routines of service providers do not need to be changed.

The integration of traditional services can also require much effort, and varying situations can occur. First, an application of the organization is able to technically integrate a business process that offers the service. In this case, business processes might be adapted, so the service can be offered with this application. The decision whether a service is going to be integrated or not depends on its ability to be adapted and the effort which is needed to elaborate the required interfaces. Second, a new application needs to be bought. Despite the effort described in the first case, the effort for implementing and running the application occurs.

The pure costs of incorporating services which are not IT-enabled yet can be lower than integrating e-services, but this can result in high effort when redesigning the business processes due to the resistance of service providers. That is why, from a technical point of view, the easiest way of just changing every application that does not provide web services, does not work (despite the competitive advantage of used software systems). Projects are determined by a lack of resources such as time, money or authority. This makes it very difficult or impossible to reengineer major business processes or change the IT-infrastructure.

The service matrix helps stakeholders to negotiate the portal functionalities. Thus, service providers and decision makers can discuss the effort required to build portal services from all requested services. Within this step, the effort expectancy for the portal development can be controlled.

Based on information about user needs and effort expectancy, the decision makers are able to decide on the inclusion of services into the current version or future versions of the portal. With the evolutionary characteristics
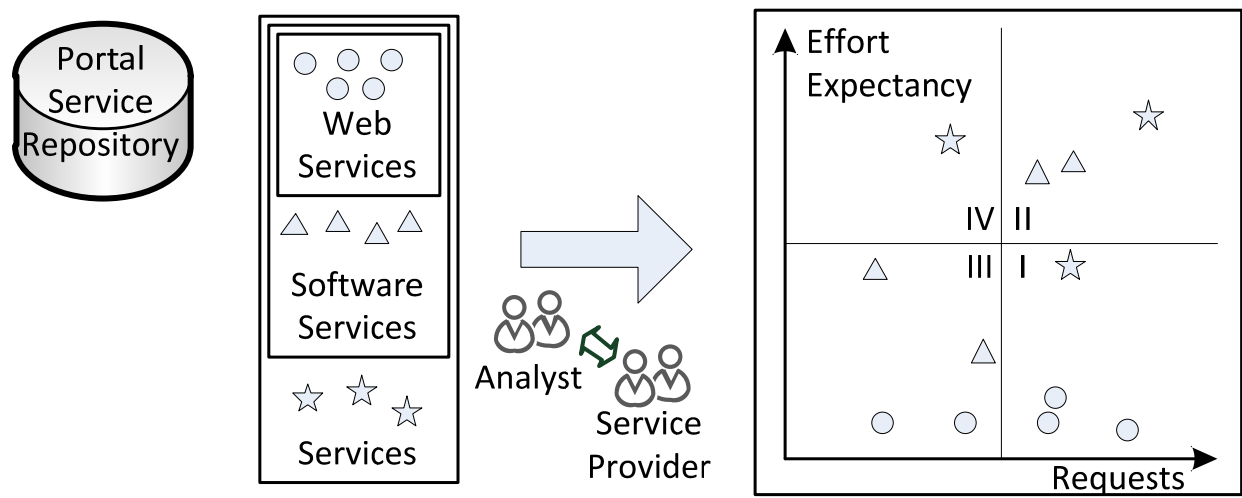

Portal Services

Figure 2. Service Matrix and Negotiation

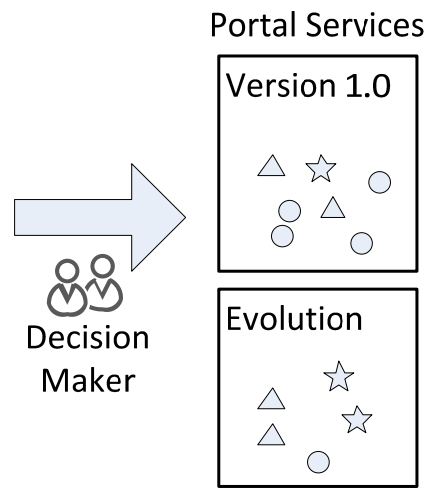


in mind, they can create the different evolutionary steps of the portal development.

The ease of integration highly qualifies web services to be considered in the first version. Considering future steps, the more requested the services are, the earlier they should be integrated (Figure 2, Sector I and II). Consequently, services that are requested less often and also very difficult to integrate might be at the end of the recent evolutionary process (Figure 2, Sector IV). Also, new services emerging from future user requirements will be considered in portal evolution. Thus, sustainability of the approach is guaranteed.

\section{Service Bundling and Portal Views}

Given the portal services which should be considered in the current version of the portal, service bundling comes into play.

A bundle from a generic perspective can be defined as "a collection of things bound or otherwise fastened together" [11]. The concept of service bundling was first dealt with in the field of marketing. Stremersch and Tellis' [12] definition of a bundle as "the sale of two or more separate products in one package" is insightful; however, within the scope of this paper, we follow the definition of Kohlborn et al. [13], who delimitate bundles from aggregations and compositions. The authors conclude that bundles are distinctively different to both aggregations and compositions, as they possess emergent properties for the whole and still have separately recognizable components. These relationships are depicted in Table 1.

The emergent properties described above play an important role for the strategic relevance of bundles. Weber [14] provides the example of a computer which consists of the following three components: the processor, the main memory, and the disk storage. As an emergent property, he presents "processing power" which has meaning only in terms of the whole, the computer, and not for its components. Still, properties of the components can have an impact on the property of the whole, which is represented by the cycle time in the processor, the access time in the main processor, and the access time in the main storage in this example. This concept of emergent properties is based on the work of Bunge [15], who identifies a number of types of properties in his search for a complete theory of properties.
TABLE I.

AdVAntage of Service BundLING

\begin{tabular}{|l|l|l|l|}
\hline \multicolumn{1}{|c|}{ Feature } & \multicolumn{1}{|c|}{ Aggregation } & Composition & Bundle \\
\hline $\begin{array}{l}\text { Separately } \\
\text { recognizable } \\
\text { components }\end{array}$ & Yes & No & Yes \\
\hline $\begin{array}{l}\text { Emergent } \\
\text { properties }\end{array}$ & No & Yes & Yes \\
\hline
\end{tabular}

As outlined, service bundles are sets of services which are fastened together for one major purpose: there is an expected additional value through emergent properties, i.e., properties which are not existent for individual services within a given bundle, but come into existence through the interplay between all services within this specific bundle. Within the portal context, these value-adding bundles can and should be derived by the users themselves. This automatically leads to a user-centric perspective.

The users are given the set of portal services that the service provider is currently able to provide and to which the decision makers are already committed. Based on this, the users are then asked to find sets of portal services which add value in a certain situation (Figure 3). The situations we are talking about do not need to fulfill specific criteria; rather, they might emerge through a life event of the portal's users, the demographic background of the users, etc.

The value adding property that emerges and which distinguishes bundles from compositions lies in the holistic representation for one specific user group. It becomes obvious that our new approach enables a portal design that provides dedicated portal service offerings for a comprehensive range of user groups. Thus, the service bundles allow an efficient use of the overall set of portal services in the portal service repository. This efficient way of service provision is enabled through the concept of service reuse which is widely accepted in the research field of service portfolio management [16].

As some portal services might be part of more than one holistic bundle, an overview of the importance of services can be easily captured and monitored. The more bundles a specific portal service is attached to, the more important it is. As a consequence, the service provider is conscious about critical services. Also, representational problems such as informational overload can be solved, as only portal services are presented which fit the users' needs. This is a topic which

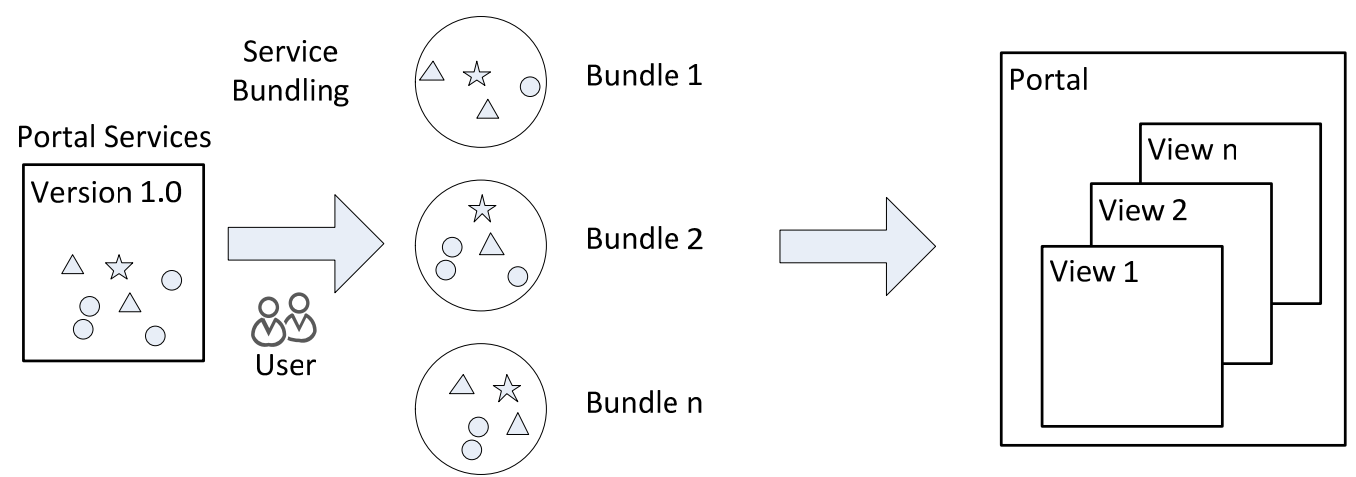

Figure 3. Service Bundling and technical views 
is discussed in detail in the fields of human computer interaction fields and usability [17].

The assignment of users to bundles should be mandatory for some bundles (e.g., bundles designed for specific roles users are assigned to). Thus, the bundles enabling the users to realize their core competencies are provided automatically. It should be optional for other bundles (e.g., bundles for which required data of the actual user is not available to the system yet, such as users' interests or additional demographic data). Of course, data privacy of all users has to be secured at all points during the process. Finally, the main benefit through the new bundling-enabled methodology lies in the increased consideration of the interests from both the service provider and the service consumer.

With respect to service consumers, users are enabled to contribute actively to the user-centric service provision, and are thereby involved in building an information architecture which fits their needs. Considering service providers, they benefit because they can concentrate on their core business of providing services and offering them in a user-friendly and convenient manner. Simultaneously, they are aware of important services and are given the opportunity to be part of a user-centric service provision at an early stage.

\section{Case Study: The Student Portal at Kassel UNIVERSITY}

This section describes the practical case in which we collect requirements and develop a portal using the described approach. The Kassel University has authorized us to plan a student portal. The infrastructure of the university is comparable to that of other big organizations. Through its uncoordinated growth, it is very heterogenic with different isolated applications for different tasks. The student portal shall offer a one-stop access to different IT-applications and services hosted or provided by the university. Additionally, the portal for students shall provide new functionality that is not available online today.

Earlier approaches to building a student portal failed because the service provider could not provide designed functionality with the given resources. Nevertheless many existing services provided by different centralized or decentralized departments could be used and rearranged in a portal to meet most user group needs.

In the first step, the offered services of the university facilities were collected. Afterwards there were two workshops conducted to systematically derive services for the student portal, which pursued following goals:

- Elicitation of required services from the point of view of the students

- Elicitation of situations in student lifecycle

- Assignment of services to important situations

The workshops were conducted with students of a master course named "Collaboration Engineering". Both workshops consisted of ten participants and each lasted four hours. To achieve the above described goals in this period of time, the survey and also the following classification was conducted in IT-supported workshops.
To directly obtain services for the portal, following lead question was asked to the student: What should students are able to do with the student portal of the University of Kassel? Therefore in the first workshop 77 (in the second workshop: 85) services were collected. After a short discussion, the participants were asked to rate the portal services for the student. This was done by assessing the particular relevance for students with the specification "low", "middle" and "high". This was the basis for the resulting ranking that assigned one, two or three points according to the specification. In this way a service ranking could be created from the point of view of the students.

Typically required services for the student portal are functionalities for exam registration, receiving news from the chairs, and to find mentors. These portal services are provided by software applications from different university facilities. For example there are different IT-applications in the departments with which students can register for exams. News are offered from the chairs on their own websites. The student office coordinates mentors and the allocation of the students.

The portal services were collected in the portal service repository. This catalogue contains web services, e-services and services. For example the departments offer their news with the help of a content management system, which provides a well described interface for remote access. Therefore this service can be classified as a web-service. The exam registration is handled by a proprietary IT-application without a suitable interface and is therefore classified as an e-service. The mentor service is not supported by any ITapplication at the moment.

Unfortunately, we could not get a decision of the decision makers about the inclusion of the portal services into the first version. That's why we decided to use the 50 percent most requested services (sector I and II in the service matrix).

After a thematic introduction to situations in student's lifecycle, the workshop participants were prepared to a brainstorming-session for identification and generation of student portal relevant life situations. The lead question was: In which situations/life events are students using a student's portal? So we were able to capture 42 (45) life situations, which were reduced to 16 (20) life situations after cleaning the list while merging similar situations.

TABLE II. TWO SITUATIONS INCLUDING THEIR 5 TOP-SERVICES

\begin{tabular}{|l|l|}
\hline \multicolumn{1}{|c|}{ Situation: Exam } & \multicolumn{1}{c|}{ Situation: Begin of studies } \\
\hline Exam related information & Fees and Funding \\
\hline Documents of previous terms & Lecturer information \\
\hline Contact administration & Accommodation \\
\hline Previous exams & Overview of courses \\
\hline Examination regulations & Contact administration \\
\hline
\end{tabular}

The participants were asked to assign the portal services to situations. Thus, the participants defined specific service bundles. Furthermore, portal services could be identified 
which play a substantial role in many service bundles. It is therefore of great interest not only for users, but also for service providers. Thus, a provision of services can follow, which is characterized by the maximization of the expectable customer benefit. Two life events, which originated in the workshop, are shown in Table II. We limit the illustration to five services, which were most often assigned to the situation.

On the basis of the resulting bundles, the views of the portal are created right now.

\section{CONCLUSION}

We have shown a new approach for designing corporate portals that combines service-oriented requirements engineering and service bundling from marketing. This approach is promising because of the possibility to validate requirements with the help of existing services. It also helps to determine the possible functionality of the portal in a fast manner. The integration of the service provider in early stages of the development process helps to avoid late and cost-intensive faults. Furthermore, the decision makers can base their decision on single functionalities on estimated effort and users' demands. In addition, the new approach is supported through the user-centric development of portal structures based on services to which decision makers are already committed. This is considered to be the main contribution of our new approach integrating service bundling. The user groups themselves create service bundles that meet their needs. Thus, user orientation is an inherent part of the new approach, whereas decision makers are integrated from the very beginning.

For future research steps, the systematic requirements engineering might inform and foster the systematic service engineering for which research methods are already being applied [18]. Also, we consecutively elaborate on the evaluation part using the presented case. First results are promising. After the case study at Kassel University is finished, we intend to test the applicability of the approach by introducing it to other contexts and organizations' portals.

\section{ACKNOWLEDGEMENT}

We thank Hesse's Ministry of Higher Education, Research, and the Arts for funding the project as part of the research funding program "LOEWE - Landes-Offensive zur Entwicklung Wissenschaftlich-ökonomischer Exzellenz". For further information, please visit: http://www.iteg.unikassel.de/venus.

\section{REFERENCES}

[1] Baida, Z., Gordijn, J., and Omelayenko, B. 2004. A shared service terminology for online service provisioning. Proc. 6th International Conference on Electronic Commerce 1-10. Delft, The Netherlands: ACM

[2] Maiden, N., "Servicing Your Requirements." Software, IEEE, vol. 23(5), 2006, pp. 14-16.

[3] Vo, H.T.K. 2007. Engineering Corporate Portals, Karlsruhe.

[4] Remus, U., "Critical Success Factors of Implementing Enterprise Portals," Proc. 39th Hawaii International Conference on System Sciences, IEEE, 2006, pp. 182-192.

[5] Terra, J. and Gordon, C., "Realizing the promise of corporate portals: Leveraging knowledge for business success," ButterworthHeinemann 2003.

[6] Amberg, M., Holzner, J., and Remus, U., "Portal-EngineeringAnforderungen an die Entwicklung komplexer Unternehmensportale," Proc. Wirtschaftsinformatik, Physica, 2003.

[7] Aier, S., Bucher, T., and Winter, R., "Kritische Erfolgsfaktoren für die Gestaltung serviceorientierter Informationssysteme." Wirtschaftsinformatik, vol. 53(2), 2011, pp. 75-87, doi:10.1007/s11576-011-0263-5.

[8] Gurzki, T., Hinderer, H., Kirchhof, A., and Vlachakis, J., "Die Fraunhofer Portal Analyse und Design Methode (PADEM)-Der effiziente Weg vom Prozess zum Portal." Fraunhofer IAO, vol. 221, 2004.

[9] Zachos, K., Maiden, N., Zhu, X., and Jones, S., "Discovering web services to specify more complete system requirements," Proc. CAiSE, LNCS 4495, Springer, 2007, pp. 142-157.

[10] Zachos, K. and Maiden, N., "Inventing Requirements from Software: An Empirical Investigation with Web Services," Proc. 16th International Requirements Engineering Conference, IEEE, 2008, pp. 145-154.

[11] Simpson, J. and Weiner, E. 1989. The Oxford English Dictionary. Oxford, UK: Oxford University Press.

[12] Stremersch, S. and Tellis, G.J., "Strategic bundling of products and prices: A new synthesis for marketing." The Journal of Marketing, vol. 66(1), 2002, pp. 55-72.

[13] Kohlborn, T., Luebeck, C., Korthaus, A., Fielt, E., Rosemann, M.et.al., "Conceptualising a bottom-up approach to service bundling," Proc. 22nd International Conference on Advanced Information Systems Engineering, 2010.

[14] Weber, R., "Ontological foundations of information systems," Melbourne, Australia: Coopers \& Lybrand 1997.

[15] Bunge, M., "Ontology I: The Furniture of the World," vol. 3, Hingham: D. Reidel Publishing Company 1977.

[16] Kohlborn, T., Fielt, E., Korthaus, A., and Rosemann, M., "Towards a service portfolio management framework," Proc. 20th Australasian Conference on Information Systems, 2009, pp. 195-202.

[17] Nielsen, J., "Usability engineering," Boston: Acad. Press 1993.

[18] Menschner, P., Peters, C., and Leimeister, J.M. 2011. Engineering Knowledge-Intense, Person-Oriented Services - A State of the Art Analysis. 19th European Conference on Information Systems (ECIS 2011). Helsinki, Finnland. 